\title{
Integrated system of non-contact thermal control of the units of self-contained locomotives
}

\author{
Sergei Ovcharenko ${ }^{1, *}$, Oleg Balagin ${ }^{1}$, Dmitrii Balagin ${ }^{1}$, and Viktor Vedruchenko ${ }^{1}$ \\ ${ }^{1}$ Omsk State Transport University, Karl Marx Ave., 35, Omsk, 644046, Russia
}

\begin{abstract}
The stages of implementation of the integrated system of noncontact thermal control of the main units and systems of self-contained locomotives are considered. The developed techniques for assessing the technical state of sections of radiators, electrical machines, and highpressure fuel equipment of self-contained locomotives using the thermal imaging control method are presented.
\end{abstract}

\section{Introduction}

One of the tasks of reforming JSC "Russian Railways" is to increase the efficiency of all the parts of a single complex - the transportation process [1]. Locomotive economy takes one of the leading places. The current situation with the technical state of the fleet of selfcontained locomotives (diesel locomotives) requires solving a number of important technical problems associated with increasing the efficiency of their use. The maintenance of the required level of reliability of the diesel locomotive fleet in operation largely depends on the technologies that are used both in the repair industry and in the process of diagnosing the units and systems of self-contained locomotives.

\section{Experimental section}

At the department "Locomotives" of the Omsk State Transport University, the direction of diagnosing units and systems of self-contained locomotives with non-contact thermal methods of control is actively developing.

With the aim of implementing an integrated system of non-contact thermal control of the main units and systems of diesel locomotives, techniques have been developed for assessing the technical state of the radiator sections of the cooling system, electrical machines, and high-pressure fuel equipment of diesel locomotives using the thermal imaging control method.

Cost-effective operation of diesel locomotives under operating conditions largely depends on the technical condition of the elements of high-pressure fuel equipment [2]. During operation, the main components of the high-pressure fuel pump (HPFP) (plunger pair, discharge valve) and nozzles (precision pair "needle-housing", slotted filter) are

\footnotetext{
* Corresponding author: ovcharenkosm@mail.ru
} 
subject to wear and clogging with abrasive particles. As a result, the quality of the working process in the diesel cylinder deteriorates, the level of the cylinder output is reduced, the specific effective fuel consumption is increased, and the life of the diesel engine is reduced. Operative non-contact control with a minimum of auxiliary operations and time allows avoiding the above effects.

As a diagnostic parameter for assessing the technical state of the HPFP and the nozzle, the surface temperature of pipeline of the high pressure fuel system was assumed $-t_{i}^{(j)}$ [3].

Thermal imaging should be carried out under a heat transfer regime close to stationary one. Stationarity of the process is achieved by heating the diesel engine at the nominal position of the driver's controller within 15-30 minutes until the temperature values of the water and diesel oil are stabilized. During the test, it is necessary to record the value of the outdoor temperature. The algorithm for processing the results of thermography and giving the findings on the technical condition of the fuel equipment (FE) of the locomotive is shown in Fig. 1.

It is recommended to carry out the control process when the locomotive is located in the locomotive depot area before or after the maintenance MNT-3, current works CW-1, CW-2, and CW-3 [4]. The monitoring allows identifying in time HPFP and nozzles that do not provide a high-quality diesel working process, which makes it possible to quickly restore the necessary power, economic, and environmental characteristics of a diesel locomotive's diesel engine.

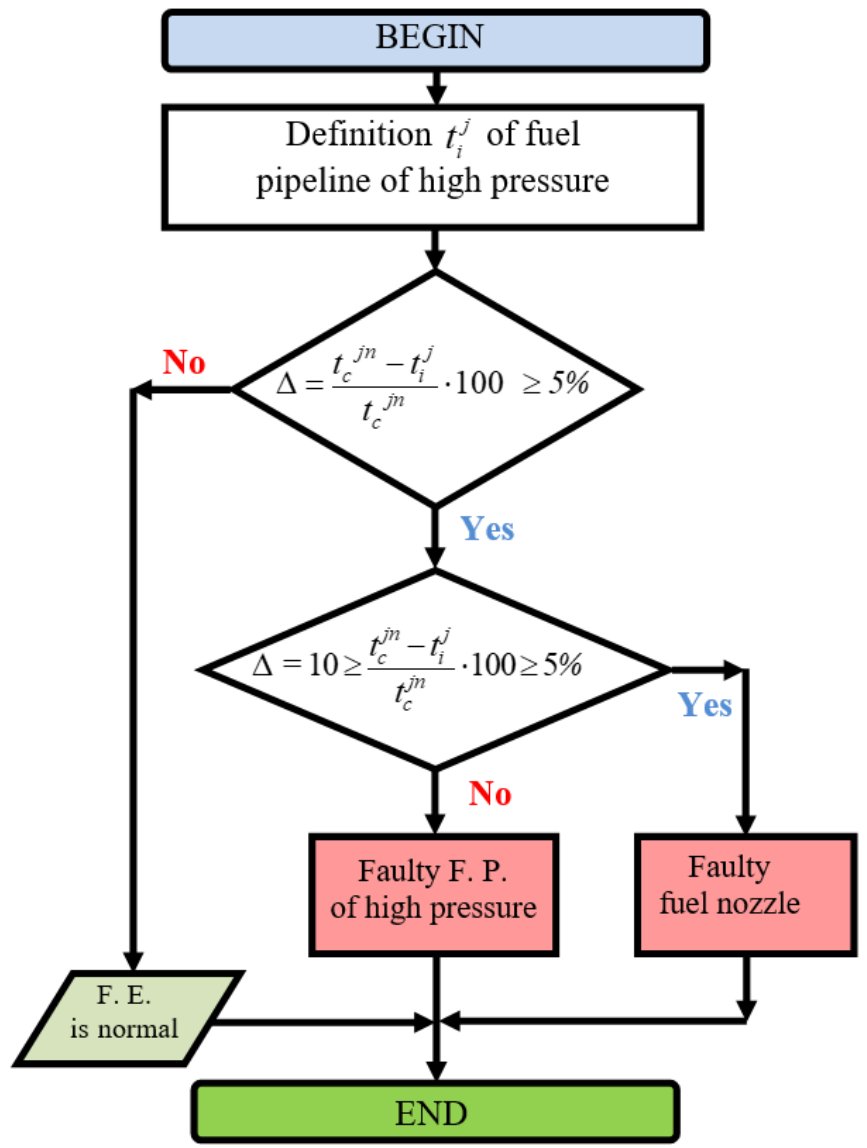

Fig. 1. Algorithm for processing the results of thermography of diesel engine FE. 
In addition, the operational control of technical condition of the FE makes it possible to assess the quality of repairs and, if necessary, take appropriate measures to improve technical condition of the diesel locomotive's fuel system [5].

To calculate temperature of the wall surface of the high-pressure fuel pipe of the i-th cylinder, the following notation is introduced:

$t_{c}^{j n}$ - the design normative value of the pipeline surface temperature of a fault-free fuel system at the $\mathrm{j}$-th temperature.

The obtained results of mathematical modeling of the surface temperature of the high pressure fuel pipeline [4] show that the deviation of the surface temperature of the pipeline of the fuel system with a faulty HPFP from the surface temperature of the pipeline with a fault-free fuel system ranged from $10.4 \%$ to $14.3 \%$. As a boundary value of the deviation of the temperature of the fuel system pipeline with a faulty HPFP, a value of $10 \%$ is assumed.

The deviation of the surface temperature of the pipeline of the fuel system with a faulty nozzle from the surface temperature of the pipeline with a fault-free fuel system is in the range from $5.8 \%$ to $9.2 \%$. As a boundary value of the deviation of the temperature of the pipeline of the fuel system with a faulty nozzle, a value of $5 \%$ is assumed.

Increasing the reliability of electric machines (including traction electric motors (TEM)) under operating conditions also contributes to reducing the number of failures in the route and unplanned repairs of diesel locomotives.

A significant number of failures of TEM occur due to the melting of brazing alloy from the commutator riser $-13 \%$ of the total number of failures [6]. This kind of malfunction arises from the fact that the engine is loaded extremely unevenly, which in turn leads to large fluctuations in the temperature of the anchor of the electric machine. A significant role is played by high vibration levels of TEM in the vertical and horizontal planes.

As a result of the mathematical modeling of the operation of TEM [7, 8], a new diagnostic parameter was proposed and justified - the difference between the temperature at the surface of the commutator and the temperature at the surface of the commutator riser $\Delta t_{i}^{(i)}$. Functional relationships between the technical state of the traction motor anchor and the temperature drop between the commutator surface and the commutator riser surface were established. The critical value of the degree of soldering of the contact connection at which the failure of the traction motor can occur is established. Conclusion on the technical state of the soldered connections of the anchor is made in accordance with the algorithm presented in Fig. 2. [9].

Since there are no means allowing to reliably estimate the technical state of the connections in question in the process of acceptance testing of TEM at present, it is recommended to perform thermal imaging inspection after undergoing repairs in the volume of CW-3, MR (medium repairs) and OR (overall repairs), not only for TEM of direct current with soldered connection of the commutator riser with the leads of the anchor winding, but also in TEM in which this type of connection is made by welding. Because in the contact of the riser with the anchor winding leads made by welding, due to the influence of operating factors reducing the reliability of TEM, it is also possible to break the integrity of the contact.

Steady operation of diesel locomotives largely depends on the quality of the cooling system, the efficiency of which decreases during operation, which leads to the operation of the diesel engine at a high temperature of the heat-transfer fluid, a decrease in the reliability of locomotives, a reduction in the power of the power plant, and, consequently, a deterioration in the fuel efficiency of the diesel. A significant contribution to the solution of this problem was made by A. I. Volodin, V. A. Chetvergov, V. A. Perminov, V. G. Grigorenko, N. I. Panov, A. P. Tretyakov, Yu. A. Kulikov and others. [10]. 


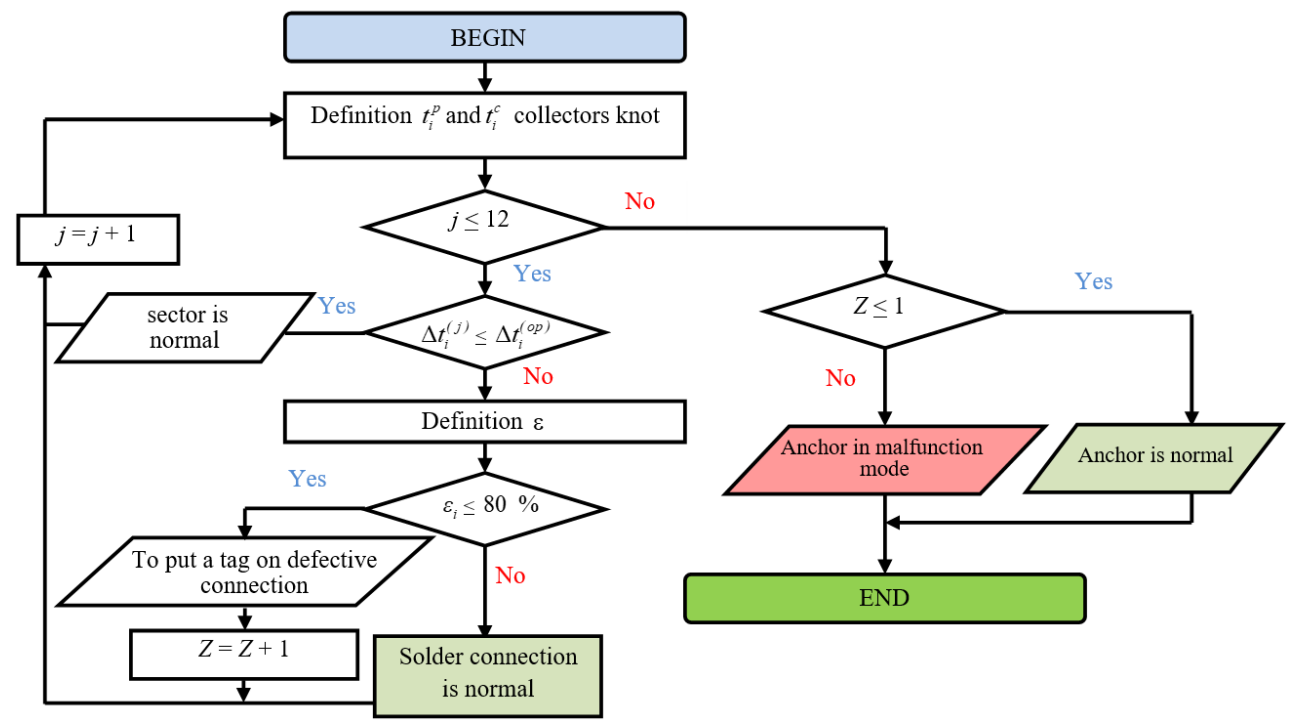

Fig. 2. Algorithm for assessing the technical condition of an electrical machine anchor.

The main elements of the diesel locomotive cooling system, which determine the efficiency of its operation, are the radiator sections. During operation, the heat dissipating capacity of individual sections of the diesel locomotive radiator is reduced [11, 12]. herefore, it is necessary to conduct periodic operational monitoring of the technical condition of the diesel locomotive radiator in order to identify faulty sections.

Based on the results of the studies, a new diagnostic parameter has been proposed and justified for carrying out thermal imaging inspection of sections of the diesel locomotive radiator - the temperature driving force of the tube wall of the section $\Delta t_{p}^{j}[13,14]$. Fig. 3 shows the algorithm for assessing the technical state of the cooling system of self-contained locomotives.

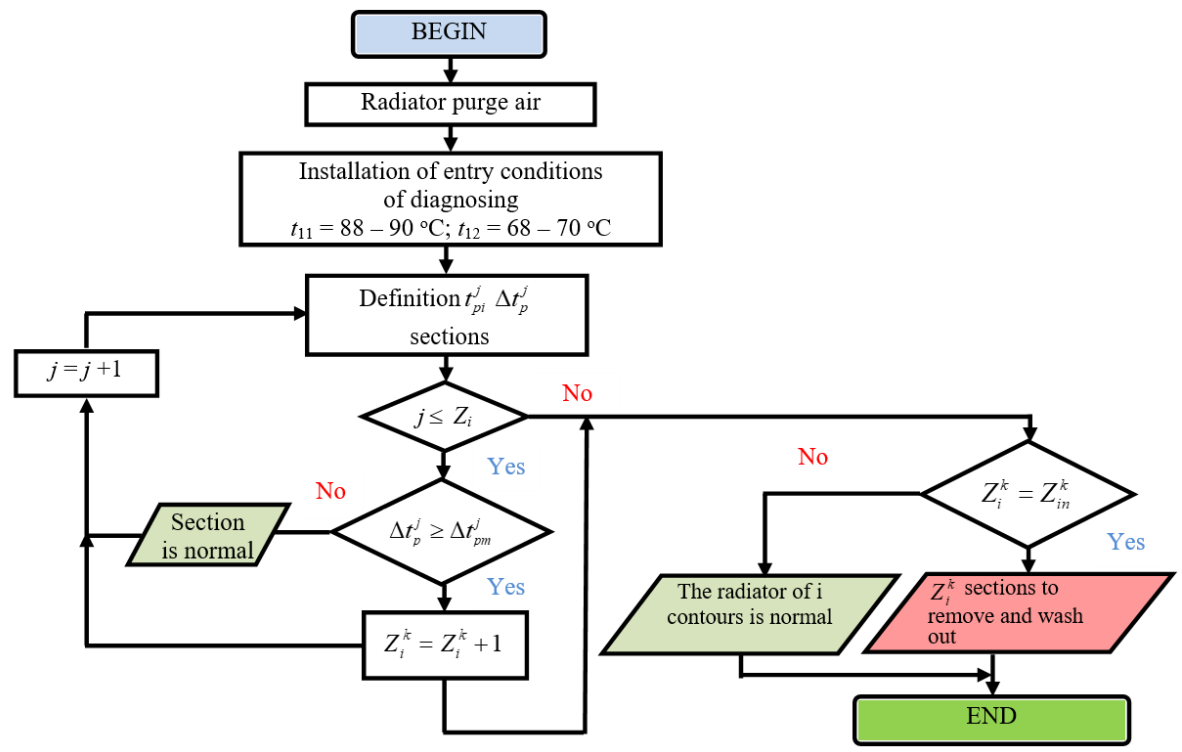

Fig. 3. Algorithm for assessing the technical state of the diesel locomotive cooling system. 


\section{Results and discussion section}

For practical implementation of the proposed technology for monitoring the technical condition of fuel equipment, specialized software has been developed (Fig. 4). The software package allows processing the results of thermography obtained from infrared receivers of different manufacturers (TESTO, FLIR, FLUKE, IRTIS-2000 ME).
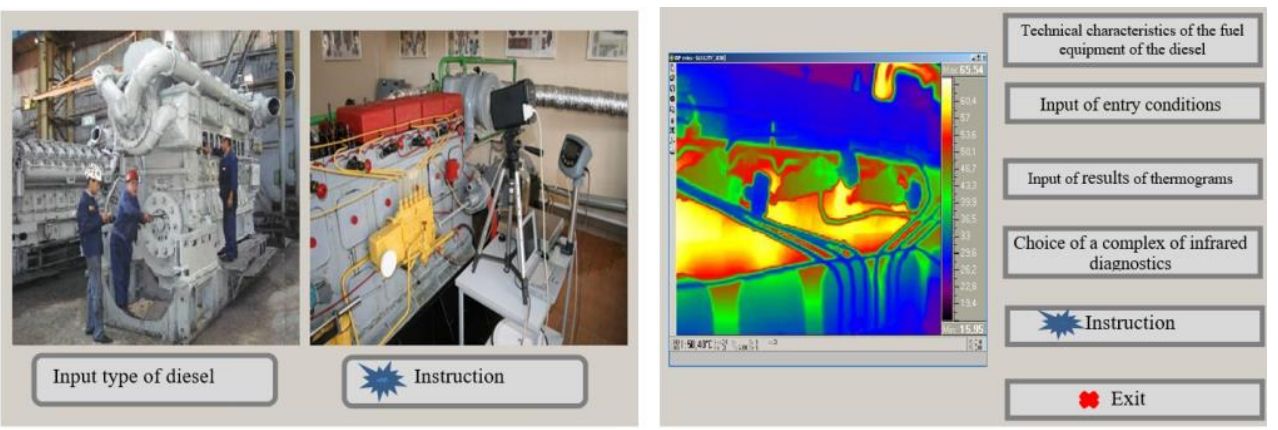

Fig. 4. Software package for control the technical state of fuel equipment of diesel locomotives using infrared receivers.

The results of the practical application of technology for monitoring the technical condition of fuel equipment are shown in Fig. 5.
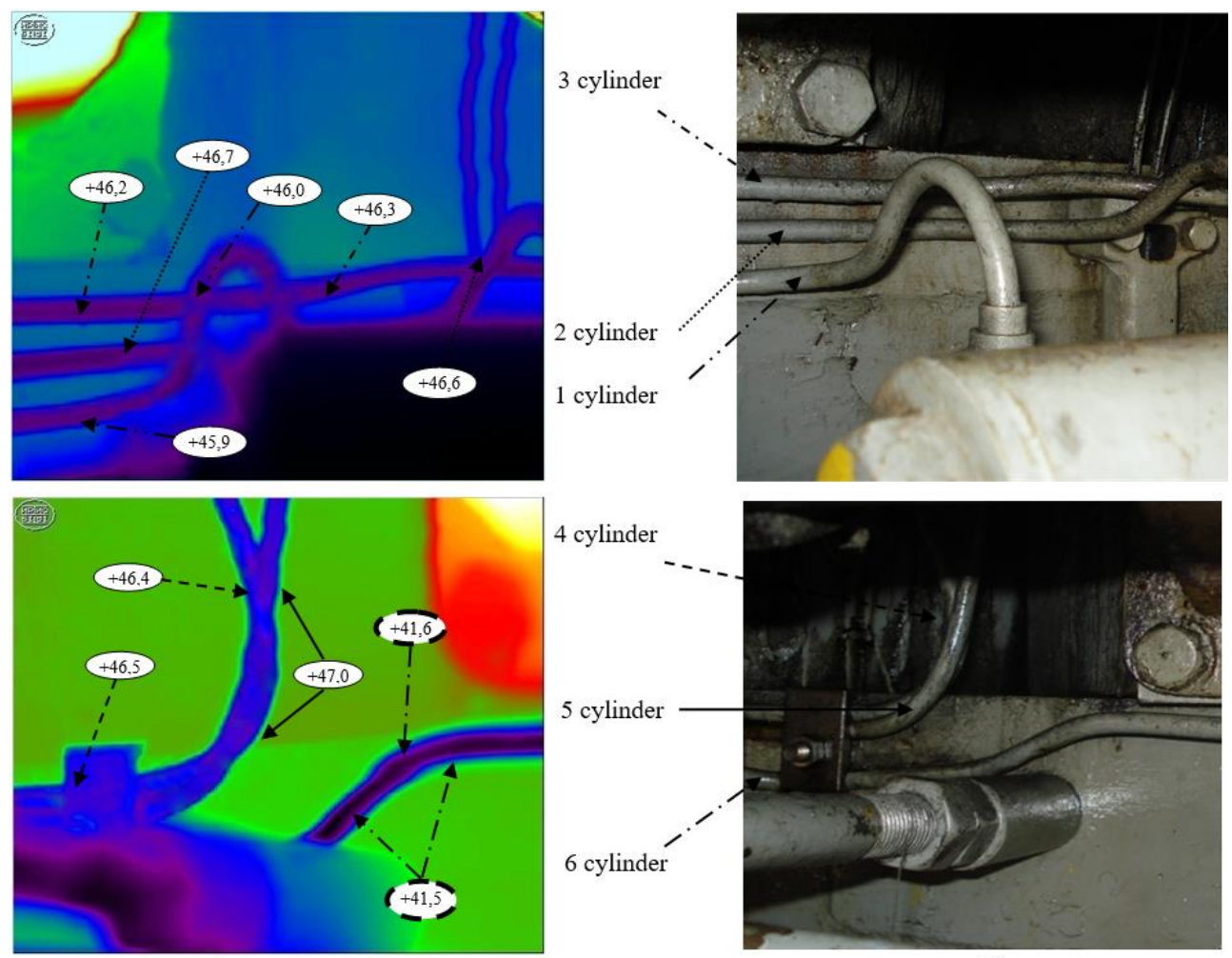

a)

b)

Fig. 5. The injection pipelines of PD4D diesel engine of TEM18DM-770 diesel locomotive (SLD Moskovka, Omsk) (defective HPFP of 6 cylinder): a) - thermogram; b) - Photo. 
The results of practical application of the technique for assessing the technical state of the EM anchor are shown in Fig. 6.

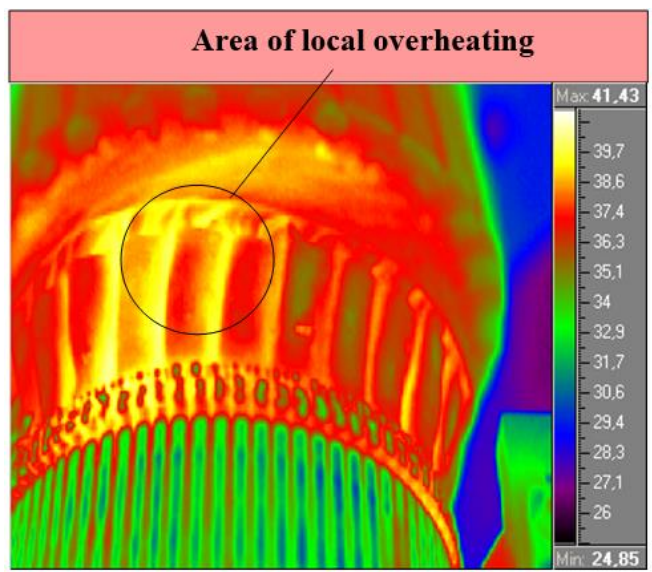

a)

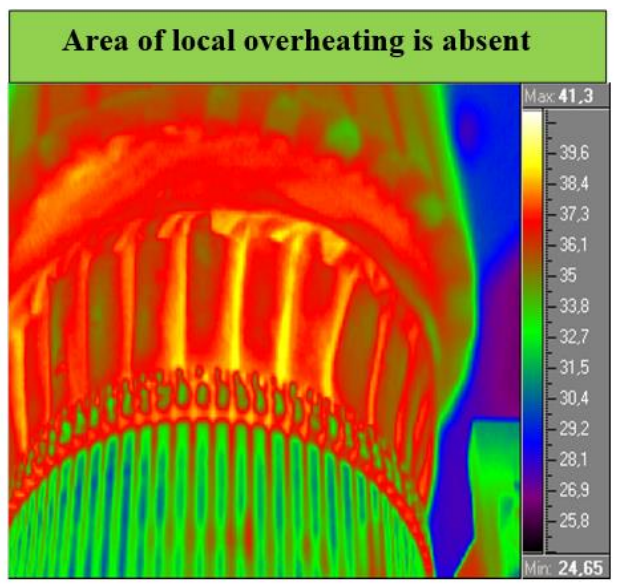

b)

Fig. 6. Thermograms of the 4th and 3rd anchor sectors after 15 min warm-up: a) - a group of commutator risers and the leads of anchor winding with an increased heating temperature; $b$ ) the region of uniform temperature distribution along the commutator and the leads of anchor winding.

Fig. 7 shows the results of the technique for assessing the technical state of the diesel locomotive cooling system.

It is recommended to carry out the diagnostic process when the diesel locomotive is at the rheostat test station at CW-2 and CW-3 $[15,16]$. Diagnostics at the CW-2 will allow identifying in time sections that do not provide the necessary heat-dissipating ability, and thereby prevent an increase in power take-off on the fan drive, exclude an increase in fuel consumption by $1-1.5 \%$, and prevent possible overheating of the diesel in operation [17].

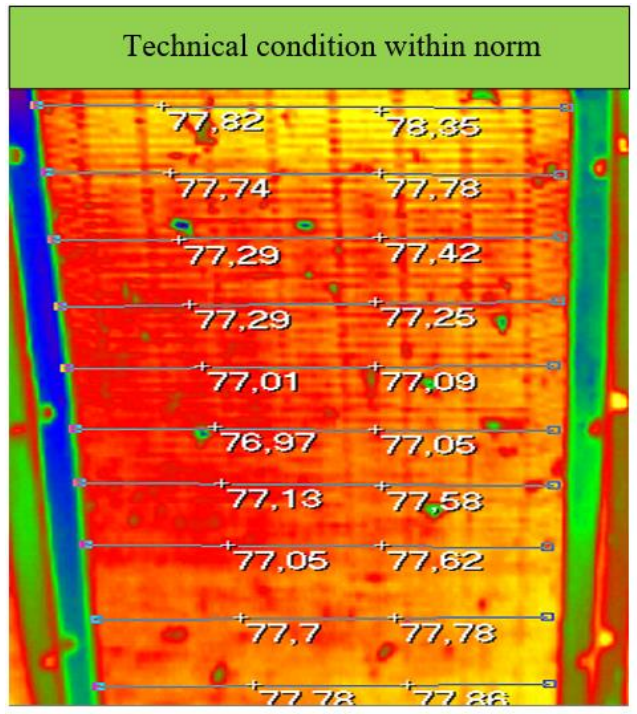

a)

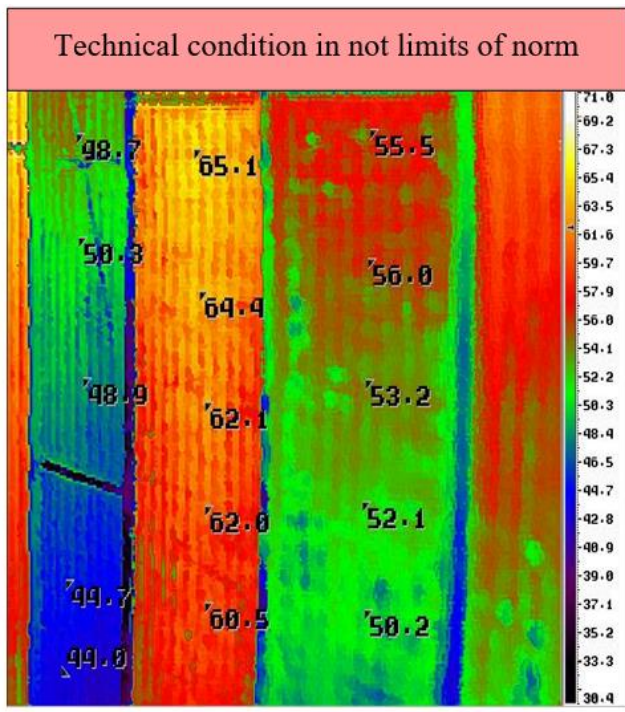

b)

Fig. 7. Thermograms of the short section of the primary circuit: a) - technical condition within the limits of norm; b)- clogging of the section tubes. 


\section{Conclusions}

1. The results of the studies made it possible to establish new diagnostic parameters for assessing the technical condition of a number of diesel locomotive units and systems discussed above.

2. The results of application of the presented techniques of the developed integrated system of non-contact thermal control of the units of self-contained locomotives of series TEM18, TEM2, TE10, TE116, TEP70 at the enterprises of the railway network of JSC "Russian Railways" showed their practical importance in determining the technical condition of the holding company locomotive fleet, the use of which will support the reliability of traction rolling stock at the required level and increase the efficiency of its use.

3. At the second stage of the implementation of the integrated system of non-contact thermal control, it is necessary: to develop a thermodynamic model of the diesel locomotive with the purpose of studying the thermal regimes of its units and systems under various technical conditions; to develop a unified technique for non-contact thermal control of all series of self-contained locomotives in operation on the railway network of a holding company JSC "Russian Railways"; to create the necessary unified software for the operative processing of the results of thermography and giving the findings on all the main units of locomotives that require the greatest constant control in operation.

4. Realization of the set tasks will allow developing an energy passport of a self-contained locomotive (diesel locomotive) and assessing the effectiveness of its implementation in an integrated quality management system.

\section{References}

1. Strategy of scientific and technical development of the holding company "Russian Railways" for the period until 2020 and the perspective until 2025 (2015)

2. S. Ovcharenko, O. Balagin, D. Balagin, IOP Conf. Series: Materials Science and Engineer-ing 327, 042073 (2018)

3. D.V. Balagin, Improvement of technology for controlling the technical condition of fuel equipment for diesel locomotive diesel engines, thesis of Cand. Tech. Sciences (OmGUPS, Omsk, 2013)

4. D.V. Balagin, Omsk Scientific Bulletin: Series Instruments, machines and technologies: OmSTU 3, 113 (2012)

5. D.V. Balagin, O.V. Balagin, Izvestiya Transsiba, Omsk State Transport University 4(16), 9 - 13 (2013)

6. A.I. Volodin, O.V. Balagin, V.K. Fomenko, Proceedings of the All-Russian Scientific and Practical Conference "Transport 2008", Rostov State Transport University, 7-11 (2008)

7. A.I. Volodin, O.V. Balagin, V.K. Fomenko, Transport of the Urals, Ural State University of Railway Transport 4(23), 21-24 (2009)

8. A.V. Gorin, Methods of the control of heating-performance condition of cooling devices of diesel locomotives in operation, Dissertation of the candidate of tehn. Sciences (VNIIZhT, Moscow, 2016)

9. V.K. Fomenko, Development of technology of thermal imaging control of technical condition of anchors of traction electric motors of locomotives, dis. Cand. Tech. Sciences (Omsk, 2009)

10. V.A. Chetvergov, O.V. Balagin, D.V. Balagin, Izvestiya Transsiba. Scientific journal, Omsk State Transport University 4(20), 72-79 (2014) 
11. S. Ovcharenko, O. Balagin, D. Balagin, IOP Conf. Ser.: Earth and Environmental Science 90, 012011 (2017)

12. S.M. Ovcharenko, O.V. Balagin, D.V. Balagin, Izvestiya Transsiba. Scientific journal, Omsk State Transport University 1(29), 27-35 (2017)

13. S.M. Ovcharenko, O.V. Balagin, D.V. Balagin, Izvestiya Transsiba. Scientific journal, Omsk State Transport University 3(23), 38-44 (2015)

14. O.V. Balagin, Development of technology of thermal imaging control of the technical state of sections of diesel locomotive refrigerators, dis. Cand. Tech. Sciences (2005)

15. S.M. Ovcharenko, O.V. Balagin, D.V. Balagin, Materials of the third all-Russian scientific and technical Conference with international participation (Omsk State Transport University, Omsk, 2015)

16. S.M. Ovcharenko, O.V. Balagin, D.V. Balagin, Transport-2015: Proceedings of the International Scientific and Practical Conference, Part 2: Engineering sciences, 229231 (2015)

17. A.I. Volodin, O.V. Balagin, V.K. Fomenko, ROAT MIIT 1, 27-31 (2009) 